\title{
THE USE OF NONSYMMETRICAL JETS FOR THE STABILIZATION OF LOW GRADE COAL FLAMES
}

\author{
C.-K. WU, L.-F. CHEN, J. LI, H.-Y. WANG \\ J.-B. WEI, H.-Q. ZHAN AND F.-Y. ZHU \\ Institute of Mechanics \\ Chinese Academy of Sciences
}

\begin{abstract}
Two new aerodynamic methods of flame stabilization have been developed which are especially suitable for low grade pulverized coals or coal-water-slurries. One is based on the Coanda effect, which causes the flat inlet jet of air to attach to the bottom of the precombustion chamber and creates a large recirculation in the upper half of the chamber with strong turbulence and mixing. The inertia of the coal particles projects them into the high temperature zone, thus they quickly ignite and burn, leading to a stable flame. The other is based on an off-axis, slightly tilted primary jet, which produces a three-dimensional flowfield with large recirculation and good mixing. The distribution of coal is also favorable for stable combustion.

Precombustion chambers employing these methods have been demonstrated to be capable of stably burning low grade coals with volatiles less than $15 \%$ and ash content higher than $30 \%$ in unpreheated combustion air. The construction is very simple, and no extra support such as compressed air, which was necessary on the previously developed method of coflowing jets with large velocity differences, is needed.

Both these methods have been developed through experimental and computational cold flow studies, laboratory combustion tests and industrial scale tests. LDV studies were made in plexiglas models, and numerical simulation corroborated the experimental results. With their usefulness and reliability demonstrated on industrial installations, many utility and industrial boiler operators in China are installing them for startup and part-load flame stabilization to conserve the large quantity of oil presently used for these purposes.
\end{abstract}

\section{Introduction}

The significance of being able to burn low grade coals effectively and efficiently in China has been

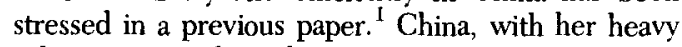
reliance on coal as the major energy source $(70 \%$ of total energy, over $9 \times 10^{8}$ tons produced annually) and acute energy shortage as evidenced by the very low per capita energy consumption (0.6 ton std. coal equi. per year), has to utilize all kinds of coal she produces, including large amount of low grade coal. These may be very low volatile and/or very high ash or moisture content. Most of these coals are burned in the pulverized form. Also, in the development of coal-water-slurry (CWS) technology, it may be desirable to burn CWS made from non-premium grade coals. Among the many problems encountered, the first ones are difficult ignition, unstable burning and low combustion efficiency. In recent years, many new developments to cope with these problems have been carried out with various degrees of success. Among them are swirl type precombustion chambers, bluff body flame stabilizers, etc. Reference 1 reported one very effec- tive precombustion chamber based on coflowing jets with large velocity differences which can easily burn, in unpreheated air, pulverized coal with as little as $10 \%$ volatiles.

It is well known that for stable and intensive combustion of difficult-to-burn fuels like low grade coal, it is essential that the following conditions are met:

1) A large recirculation zone of the high-temperature burned gases is formed.

2) Strong turbulence and good mixing are present for rapid burning.

3) The flow paths of the fuel, air and recirculating gases are such that favorable conditions in composition and temperature exist for intense combustion.

The combustor using coflowing jets with large velocity differences achieves these aims by using small, high-speed jets to entrain the primary air along one side of the chamber, thus causing a large, 3-dimensional recirculating flow pattern in the semienclosed channel (See Fig. 1). This type of precombustion chamber shows much better flame 


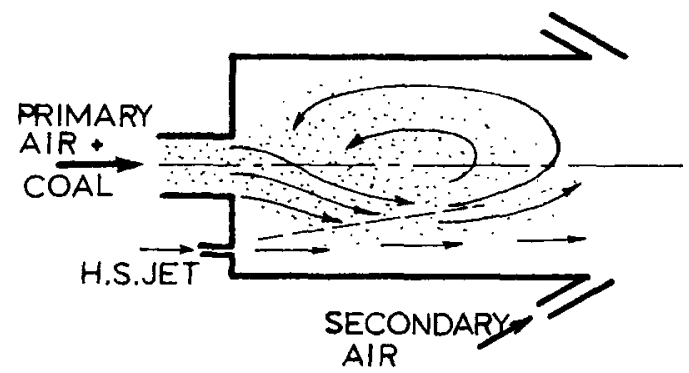

FIG. 1. Precombustion Chamber Based on $\mathrm{Co}-$ flowing Jets with Large Velocity Differences

stabilizing performance than the swirl type precombustor or the bluff body flame stabilizer. However, compressed air or steam is needed for its operation.

Recently, two new aerodynamic methods which can overcome this limitation have been developed and have been applied successfully to industrial installations. Both generate flowfields similar to those in the chamber with coflowing jets, but without using the small, high-speed compressed air jets. This paper describes the principle of these methods, cold flow LDV studies and mathematical modelling, laboratory combustion investigations and examples of tests on industrial installations.

\section{The Coanda Effect Precombustion Chamber}

This type of combustor features a flattened jet of the primary air and pulverized coal located near the center of the upstream end of a usually rectangular channel, as shown in Fig. 2. The cross section of either the jet or the channnel needs not necessarily be rectangular. The jet can be located at the midplane or it can be slightly offset. In such a configuration, within certain ranges of Reynolds number, the jet will deflect to one side and attach to the sidewall. This is the Coanda effect well known in fluidics and hydrodynamics. ${ }^{2}$ The flow pattern will be similar to that caused by entrainment by small

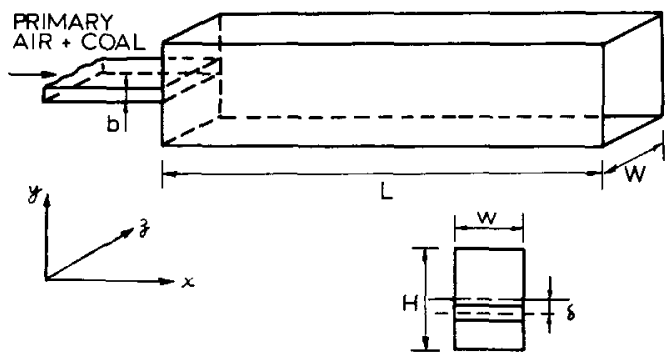

FIG. 2. Basic Configuration of the Coanda Effect Precombustor high-speed jets placed to one side, as will be shown by the following studies. In practical setups, a narrow slit is usually provided at the bottom to let in an auxiliary jet of air which will enhance the flow pattern and help sootblowing.

\section{Cold Flow Experiment:}

A plexiglas model of the combustion chamber (Fig. 2) with dimensions $\mathbf{H}=196 \mathrm{~mm}, \mathrm{~W}=132 \mathrm{~mm}$ and $\mathrm{L}=1000 \mathrm{~mm}$ has been constructed, and the flow velocity at various points on the vertical plane of symmetry was measured with a Dantec 2-D LDV system. Thickness of the jet exit (b) and location of the jet (given by $\delta$ ) were varied during the test. Some typical results of the tests are given in Figs. 3 and 4.

From these figures it can be seen that even with symmetrical inlet, the jet veered to one side and becomes attached to the wall. Continuity of mass requires that a reverse flow region be formed on the opposite side. The length of the reverse flow zone was at least $5 \times \mathrm{H}$, where $\mathrm{H}$ is the channel height.

The turbulence intensity was high in the sections where reverse flow was present, and decreased beyond these regions. Figure 4 shows the values of $u^{\prime}$ and $v^{\prime}$, nondimensionalized by the jet inlet velocity, measured with the LDV system. Notice that these fluctuating velocities, if compared with local average velocity, reached very high relative values, especially near the boundary between the forward and reverse flows. The measured values of $u^{\prime}$ and $v^{\prime}$ at the same location are of the same order of magnitude, which was not the case in the flowfield of coflowing jets with large velocity differences, where $v^{\prime}$ was found to be much larger than $u^{\prime}$ or $w^{\prime}$.

The measurements were made only on the middle plane of symmetry, and do not represent the whole picture. The flow was really 3-dimensional, and may involve recirculation in the horizontal and cross-sectional planes. These recirculations should have a beneficial effect on flame stabilization and combustion because they promote mixing of the burned and unburned streams.

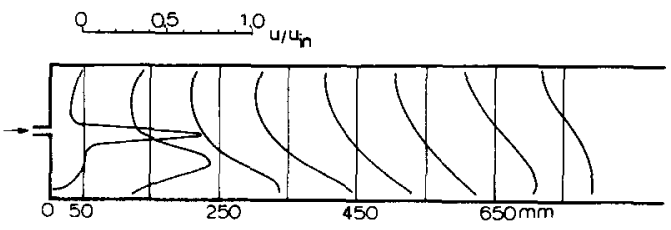

FIG. 3. Velocity Profiles Measured with LDV on the Central Vertical Plane of the Model Coanda Effect Chamber $(\mathrm{H}=196 \mathrm{~mm}, \mathrm{~W}=132 \mathrm{~mm}, \mathrm{~L}=$ $1000 \mathrm{~mm}$ )

$$
\mathrm{b}=10 \mathrm{~mm}, \delta=0, u_{\text {in }}=14 \mathrm{~m} / \mathrm{s}
$$




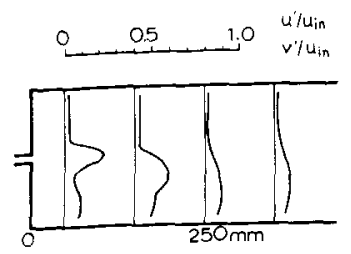

(a) $u^{\prime} / u_{\text {in }}$

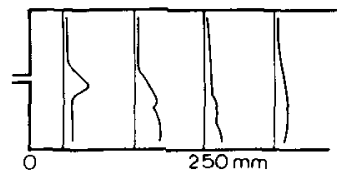

(b) v'lu in
FIG. 4. Turbulence Intensity Measured with LDV, Conditions Same as in Fig. 3

\section{Numerical Modelling of the Cold Flowfield:}

A 2-dimensional K- $\epsilon$ model of the turbulent flat jet in a semienclosed channel was used to obtain the basic features of the flowfield of the Coanda effect combustion chamber. One case of special interest is where the geometry is symmetrical about the centerline - the jet is located exactly midway between the upper and lower walls.

The basic equations in two dimensions were expressed in the general form

$$
\frac{\partial}{\partial x_{j}}\left(\rho v_{j} \phi\right)=\frac{\partial}{\partial x_{j}}\left(\Gamma_{\phi} \frac{\partial \phi}{\partial x_{j}}\right)+S_{\phi}
$$

with the meaning of the symbols as shown below:

\begin{tabular}{lcc}
\multicolumn{1}{c}{ Equation } & $\phi$ & $\Gamma_{\phi}$ \\
Continuity & 1 & 0 \\
$x$-Momentum & $u$ & $\mu_{\text {eff }}$ \\
$y$-Momentum & $\nu$ & $\mu_{\text {eff }}$ \\
K-Transport & $\mathrm{K}$ & $\mu_{\text {eff }} / \sigma_{K}$ \\
$\epsilon$-Transport & $\epsilon$ & $\mu_{\text {eff }} / \sigma_{\epsilon}$
\end{tabular}

where

$$
\begin{aligned}
\mu_{\mathrm{eff}} & =\mu_{l}+\mu_{t}, \quad \mu_{t}=\mathrm{C}_{\mu} \rho \mathrm{K}^{2} / \epsilon \\
\mathrm{G} & =\mu_{t}\left(\frac{\partial v_{i}}{\partial x_{j}}+\frac{\partial v_{j}}{\partial x_{j}}\right)\left(\frac{\partial v_{i}}{\partial x_{j}}\right) \\
\sigma_{\epsilon} & =K^{2} /\left(\mathrm{C}_{2}-\mathrm{C}_{1}\right) \mathrm{C}_{\mu}^{1 / 2}
\end{aligned}
$$

The values of the empirical constants used in these equations were:

$$
\begin{array}{cccccc}
\mathrm{C}_{1} & \mathrm{C}_{2} & \mathrm{C}_{\mu} & \sigma_{k} & \sigma_{\epsilon} & \mathrm{K} \\
1.44 & 1.92 & 0.09 & 1.0 & 1.1 & 0.4
\end{array}
$$

The boundary conditions at the inlet were given by the empirical relations

$$
\begin{aligned}
\mathrm{K}_{\mathrm{in}} & =0.03 u_{\mathrm{in}}^{2}, \quad \epsilon_{\mathrm{in}}=\mathrm{K}_{\mathrm{in}}^{3 / 2} / 0.005 b \\
u & =u_{\text {in }}, \quad \nu=0
\end{aligned}
$$

At the exit, fully developed turbulent chamber flow was assumed with all axial gradients set to zero. On the walls, the velocity components and turbulence were set to zero.

Finite difference method based on the finite control volume by Patankar and Spalding ${ }^{3}$ was used for the numerical solution of the flowfield. A staggered grid was used for $u$ and $v$. The $p$-V iteration process was used for the solution of the variable $\phi$. Grid spacing was finer in the front portion of the chamber, where recirculations were likely to be present. A semi-empirical wall function was employed to accommodate the rapid variation of the parameters near the wall, thus avoiding some computational difficulties.

Numerical experiments with varied geometry and inlet velocity were performed. Only one typical result of computation is shown in Fig. 5. It is interesting to note that the computed result shows that

$\mathrm{S}_{\phi}$
0
$-\frac{\partial p}{\partial x}+\frac{\partial}{\partial x}\left(\mu_{\text {eff }} \frac{\partial u}{\partial x}\right)+\frac{\partial^{2} \nu}{\partial y \partial x}$
$-\frac{\partial p}{\partial y}+\frac{\partial}{\partial y}\left(\mu_{\text {eff }} \frac{\partial \nu}{\partial y}\right)+\frac{\partial^{2} u}{\partial y \partial x}$
$\mathrm{G}-\rho \epsilon$
$\frac{\epsilon}{\mathrm{K}}\left(\mathrm{C}_{1} \mathrm{G}-\mathrm{C}_{2} \rho \epsilon\right)$

the jet veers to one side and attaches to the wall, behaving just like the real jet.

There is a small recirculation zone on the side of jet attachment, and a very large recirculation on the opposite side. The computed results are in reasonable agreement with the measured ones.

\section{Laboratory Combustion Tests:}

A refractory-lined rectangular combustion chamber of dimensions $200 \times 160 \times 800 \mathrm{~mm}(\mathrm{H} \times \mathrm{W}$ 


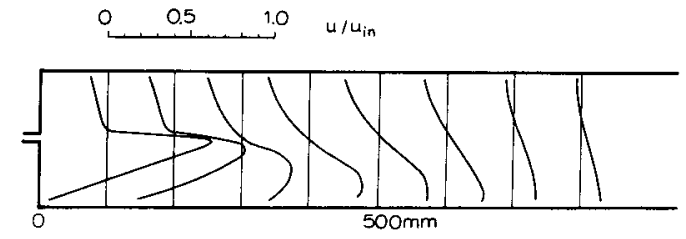

Fig. 5. Computed Velocity Profiles in 2-dimensional Flow, Given Conditions Same as in Fig. 3

$\times \mathrm{L})$ in modular construction was used in the laboratory tests. Thermocouples were used for measuring the temperature field. For comparison of flame-stabilizing abilities of various configurations, three types of inlet were tested: a flat jet (Coanda effect burner), a round jet with the same cross sectional area, and a round jet with a bluff body (cylindrical rod) across the jet exit. A series of tests were run with premixed gaseous fuel (LPG), the results of lean blowout limit are shown in Fig. 6 . The flat jet showed much better flame stability than the round jet. Although the round jet with bluff body showed blowout limits about the same as the flat jet, the situation near blowoff was actually quite different. With the flat jet, the flame stayed close to the jet exit until extinction, whereas with the bluff body, the flame moved far downstream way before extinction and took the form of a lifted flame near the exit of the chamber. Measurements of the temperature distribution showed this clearly.

Since premixed gaseous fuel follows the air movement quite well and the residence time required for ignition is small as compared with coal, its behavior in flame stabilization is quite different from that of coal. In the LPG tests, it is clear that the small recirculation zone on the jet attachment side was the main source of ignition and flame stabilization.

When pulverized coal was tested in the same chamber, the mechanism of flame stabilization was quite different. The test conditions were:

$$
\begin{aligned}
& \text { Coal: } \mathrm{V}=21 \%, \mathrm{~A}=29 \%, \mathrm{LHV}=25500 \mathrm{~kJ} / \mathrm{kg} \\
& (6100 \mathrm{kcal} / \mathrm{kg}) \\
& \text { Jet size: } 10 \times 160 \mathrm{~mm}(\mathrm{H} \times \mathrm{W}) \text {, Jet position: } \delta \\
& \quad=30 \mathrm{~mm} \\
& \text { Air flowrate }=120 \mathrm{~m}^{3} / \mathrm{h}, u_{\mathrm{in}}=20 \sim 25 \mathrm{~m} / \mathrm{s} \text {, } \\
& \quad \text { room temperature } \\
& \text { Coal flowrate }=100 \sim 150 \mathrm{~kg} / \mathrm{h}
\end{aligned}
$$

After using LPG to preheat the chamber and ignite the pulverized coal for some minutes, stable combustion of coal alone was maintained. Temperature distribution measurements showed that the large recirculation zone opposite the jet attachment side was the main source of ignition. This is due to the long heating time required for the ignition of pulverized coal and the two-phase flow behavior of the coal particles in the chamber. Cold two-phase flow studies showed that solid particles have a tendency to follow their original direction of injection while the gas turns much more easily as determined by the pressure and velocity field in the chamber. The fact that a coal with low volatiles and high ash could be stably burned with cold air in such a small test chamber indicates the good flame stabilizing property of this type of precombustor. Such flames could not have been stabilized in simple jet burners or ordinary swirl type combustors.

\section{Examples of Industrial Tests:}

The Coanda effect combustion chamber has been tested on several large utility boilers for startup, using a wide range of coals. These boilers are all of the corner-fired type. Test results are summarized in the following table and demonstrate successful use of the Coanda effect precombustor in utility boilers.

A point worth noting is that no ash or slag accumulation was observed in these tests, even with the low ash melting temperature $\left(1170^{\circ} \mathrm{C}\right)$ of the Da-Tong Power Plant. The bottom wall of the pre-

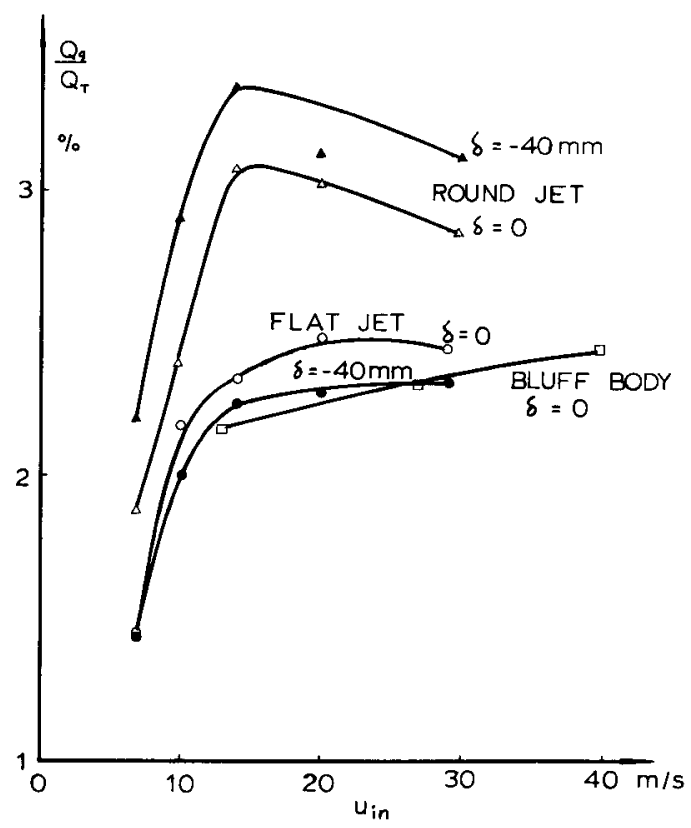

FIG. 6. Lean Blow-off Limits of Premixed LPG/ Air Flames for the Three Types of Combustors, Chamber $220 \times 160 \times 800 \mathrm{~mm}(\mathrm{H} \times \mathrm{W} \times \mathrm{L})$

$Q_{g} / Q_{\mathrm{T}}$ is the ratio of fuel flow to total flow by volume.

Mixtures leaner than the data line could not support stable combustion.

Flat Jet $b=8.5 \mathrm{~mm}$, Round Jet $\phi=40 \mathrm{~mm}$, Bluff Body $10 \mathrm{~mm}$ Cylindrical Rod in $\phi 40 \mathrm{~mm}$ Jet 
TABLE I

Industrial scale tests of the Coanda effect precombustor

\begin{tabular}{|c|c|c|c|}
\hline Power Plant & Dan-He & Da-Tong & Bao-Ding \\
\hline Boiler Size & $410 \mathrm{t} / \mathrm{h}$ & $670 \mathrm{t} / \mathrm{h}$ & $200 \mathrm{t} / \mathrm{h}$ \\
\hline \multicolumn{4}{|l|}{ Coal Used } \\
\hline Volatiles & $13.5 \%$ & $29.8 \%$ & $13 \%$ \\
\hline Ash & $18.1 \%$ & $7.4 \%$ & $33 \%$ \\
\hline \multicolumn{4}{|l|}{ Lower Heating } \\
\hline Value & $25640 \mathrm{~kJ} / \mathrm{kg}$ & $26710 \mathrm{~kJ} / \mathrm{kg}$ & $18830 \mathrm{~kJ} / \mathrm{kg}$ \\
\hline Ash Melting Temp. & $1500^{\circ} \mathrm{C}$ & $1170^{\circ} \mathrm{C}$ & $1370^{\circ} \mathrm{C}$ \\
\hline Combustion Air & Unpreheated & Unpreheated & Unpreheated \\
\hline Mounting Position of & & & \\
\hline Prechamber & Lower 2ndary air inlet & Lower 2ndary air inlet & Lower Primary air inlet \\
\hline Result of Test & $\begin{array}{l}\text { Successfully ignited } \\
\text { lower primary coal/ } \\
\text { air jet }\end{array}$ & $\begin{array}{l}\text { Successfully ignited } \\
\text { lower primary coal/ } \\
\text { air jet }\end{array}$ & $\begin{array}{l}\text { Successfully ignited middle } \\
\text { row of primary coal/air } \\
\text { jet }\end{array}$ \\
\hline
\end{tabular}

combustor was very clean. This is probably due to the airflow pattern in the prechamber, which facilitates the removal of settling particles from the chamber by blowing.

\section{Precombustion Chamber with Off-Axis Primary Jet}

The principle of this precombustion chamber is shown in Fig. 7. The primary air and pulverized coal enter the chamber through a pipe off the axis and sometimes tilted at a small angle, the velocity being about $25 \mathrm{~m} / \mathrm{s}$. A flat jet of air at about 50 $\mathrm{m} / \mathrm{s}$ is sometimes used near the bottom for soot blowing. This arrangement also creates a flowfield similar to that of the coflowing jets, thus satisfying the requirements for stable burning of low grade coals. This precombustor is very simple and gives very good flame stabilizing performance.

\section{Cold Flow Experiments:}

The Dantec 2-D LDV system was used to measure the velocity components (axial and azimuthal) at various points in a plexiglas model. The results are shown in Fig. 8.
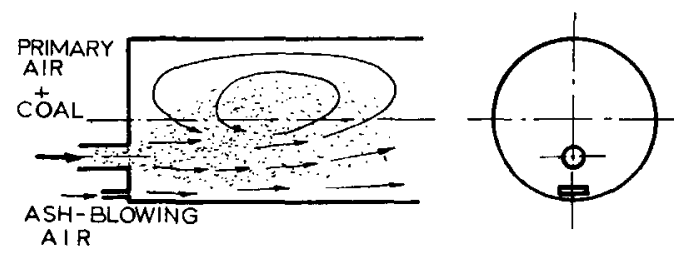

FIG. 7. Basic Principle of the Precombustion Chamber with Off-axis Primary Jet
It can be seen that in the lower half of the chamber the gas flowed downstream, and in the upper half a reverse flow region extended to at least $5 \times$ D. Furthermore, on the cross sections, there were cross flows which would further improve mixing between the forward and reverse flows. Near the entrance, the cross flow was downward, and as the flow moved downstream, the cross flow gradually reversed its direction. The flow pattern is a complicated 3-dimensional one.
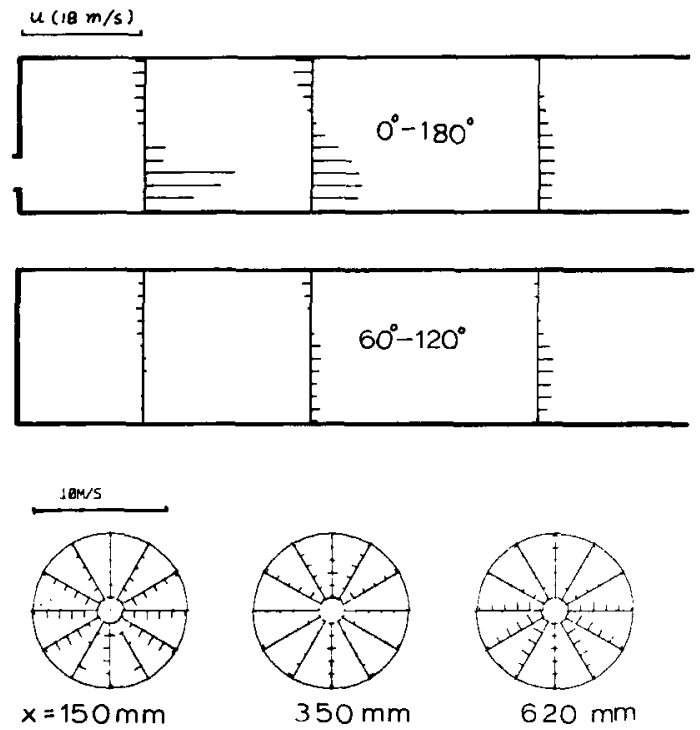

$x=150 \mathrm{~mm}$

$350 \mathrm{~mm}$

$620 \mathrm{~mm}$

FIG. 8. Velocity Profiles Measured with LDV in the Model of the Combustor with Off-axis Primary Jet, Model Chamber $\$ 186 \mathrm{~mm}, \mathrm{~L}=800 \mathrm{~mm}$, Jet Size $\phi 40 \mathrm{~mm}$, Located $45 \mathrm{~mm}$ off axis, $u_{\mathrm{in}}=18 \mathrm{~m} /$ $\mathrm{s}, \operatorname{Re}=4.9 \times 10^{4}$ 


\section{Cold Flow Numerical Modelling:}

The semi-confined turbulent flowfield of the offaxis jet has been numerically modelled. The K- $\mathrm{E}$ turbulence model of the steady, incompressible, 3D turbulent flow with equations similar to those mentioned before was used in the computation.

The control volume approach was used for discretization. Upwind differences were used for the convection terms and central differences for the diffusion terms. The velocity components $u, v$ and $w$ were positioned on a staggered mesh. A cylindrical coordinate system was used with the origin at the center of the primary jet inlet. The boundary at the chamber wall was approximated by a step-shaped wall.

The results of a typical computation are shown in Fig. 9. It can be seen that the computed results are quite similar to the measured flowfield, with the large reverse flow region in the upper half of the chamber and the cross flow which changed from downward to upward as the flow went downstream.

\section{Laboratory Tests on the Precombustion Chamber:}

Several kinds of low-volatile bituminous pulverized coal and CWS have been tested in the precombustion chamber with off-axis primary jet on the combustor teststand in the High Temperature Gasdynamics Laboratory. This teststand is equipped with the usual fuel and air supplies, observation ports and instrumentation. Coal rates up to $400 \mathrm{~kg} / \mathrm{h}$ can be tested. The chamber tested was $450 \mathrm{~mm}$ i.d., $1200 \mathrm{~mm}$ long, and refractory lined. The proximate analysis of several coals tested are
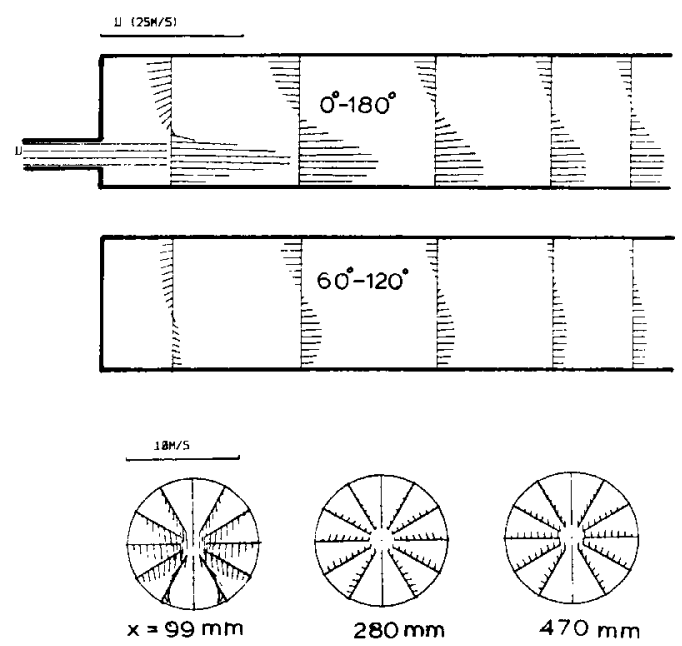

FIG. 9. Computed Velocity Profiles for the Same Model Combustor as in Fig. 8, $u_{\mathrm{in}}=25 \mathrm{~m} / \mathrm{s}$, Re $=6.8 \times 10^{4}$

$\begin{array}{lccc} & \begin{array}{c}\text { Moisture } \\ \text { W }(\%)\end{array} & \begin{array}{c}\text { Volatiles } \\ \text { V }(\%)\end{array} & \begin{array}{c}\text { Ash } \\ \text { A }(\%)\end{array} \\ \text { Bao-ding Coal } & 0.42 & 15.14 & 30 \\ \text { Huai-bei Coal } & 1.0 & 15.16 & 33.4 \\ \text { Niang-zi-guan } & 2.17 & 10.18 & 21.0\end{array}$

All the coals listed above burned stably with unpreheated air in this chamber. A typical test had a coal rate of $272 \mathrm{~kg} / \mathrm{h}$, temperature of the flame at the exit was $1350^{\circ} \mathrm{C}$, and the luminous flame extended to a distance of $2.5 \mathrm{~m}$ beyond the exit.

This type of precombustion chamber is being installed on a $410 \mathrm{t} / \mathrm{h}$ utility boiler for startup and part load flame stabilization.

\section{Example of Industrial-Scale Tests:}

After successful combustion tests in the laboratory, the precombustion chamber with off-axis primary jet was used in a test of CWS combustion on a $15 \mathrm{t} / \mathrm{h}$ industrial boiler. Two precombustors were installed on the front wall of the furnace, and an extra CWS nozzle was provided in the space in between. The test started under the condition of cold furnace and with unpreheated air. The CWS tested were made from coals with about $30 \%$ volatiles and $10 \%$ ash. Stable combustion was achieved. A cumulative 100 hour test of the boiler running on CWS had been completed, which showed viability of this approach.

\section{Concluding Remarks}

Two new aerodynamic methods of stabilizing low grade coal flames and coal-water-slurry flames have been developed in the laboratory and successfully tested on industrial installations. They feature large recirculation zones, high turbulence and good mixing, and favorable mixtures for easy ignition and flame stabilization. Low volatile bituminous and CWS can be stably burned with unpreheated air in laboratory scale precombustors, and successful industrial tests have been run. No compressed air is needed for these methods, and there is no ash or slag accumulation in the precombustor with proper adjustments. This is one further step from the previously developed method of coflowing jets with large velocity differences, and should find wide industrial application in the utility and industrial boilers and furnaces in China.

\section{Acknowledgment}

The work of this paper has been supported by the Natural Science Fund of the Chinese Academy 
of Sciences and the State Economic Commission of the People's Republic of China. The industrial scale tests were performed in cooperation with the respective plants. Mr. Sun Wen-chao, Mr. Yang Jiashou gave invaluable assistance during the investigation.

\section{REFERENCES}

1. FU, W. B., WU, C. K., et al: "The Use of Coflowing Jets with Large Velocity Differences for the Stabilization of Low Grade Coal Flames," Twenty-first Symposium (International) on Combustion, p. 567, The Combustion Institute, 1988.

2. Glaettli, H. H.: "Mach- and Cavitation Number Effects in Fluid Dynamic Elements and Circuits," Second Cranfield Fluidics Conference, Paper B8, 1967.

3. Patankar, S. V.: Numerical Heat Transfer and Fluid Flow, McGraw-Hill, 1980.
Nomenclature

$\begin{array}{ll}b & \text { Thickness of jet } \\ \mathrm{H} & \text { Height } \\ \mathrm{K} & \text { Turbulent kinetic energy } \\ \mathrm{L} & \text { Length } \\ \mathrm{M} & \text { Mach Number } \\ p & \text { Pressure } \\ \mathrm{Q} & \text { Flowrate } \\ \mathrm{Re} & \text { Reynolds Number } \\ u, v, w \quad & \text { Average velocity components in } x, y, z \\ & \text { directions, respectively } \\ u^{\prime}, v^{\prime}, w^{\prime} & \text { RMS values of fluctuating velocity in } x \\ \vec{V} & y, z \text { directions, respectively } \\ \mathrm{W} & \text { Velocity vector } \\ \delta & \text { Width } \\ & \text { Position of jet from centerline of cham- } \\ \epsilon & \text { ber } \\ \mu & \text { Dissipation rate of energy } \\ \rho & \text { Viscosity } \\ & \text { Density }\end{array}$

\section{COMMENTS}

M. Sadakata, Gunma Univ. Japan. How much reduction rate of $\mathrm{NO}_{x}$ can you obtain by your new aerodynamic method?

Author's Reply. Since the flame zone in the precombustor operates mainly in the fuel-rich regime, the production of $\mathrm{NO}_{x}$ is relatively low. In a series of tests in the laboratory, with overall equivalence ratio $\left([\mathrm{F} / \mathrm{A}] /[\mathrm{F} / \mathrm{A}]_{\text {theo }}\right)$ from 0.80 to 0.93 , the measured $\mathrm{NO}_{x}$ concentration at the chamber exit was 182 to $250 \mathrm{ppm}$. The lower $\mathrm{NO}_{x}$ values generally correspond to the richer mixtures.

N. Syred, Univ. College Carditt, United Kingdom. Does your device suffer from any deposition/ buildup/erosion problems when your Coanda jet hits the wall?

Author's Reply. We have not encountered any serious erosion problems with the unit except when operating with petroleum coke when some erosion of the exhaust nozzle was encountered. Careful control of the system is needed (via simple feedback loops controlling primary airflow via measurements of temperature) to ensure that sufficient high temperatures are not generated to cause fouling. Extended successful operation has been carried out with coals whose ash fusion temperature are greater than 1100 to $1150^{\circ} \mathrm{C}$. We would not normally op- erate in a non-slagging mode with coals of a lower ash fusion temperature. Some problems have been encountered with fouling in the exhaust nozzle; such deposits can be routinely removed by appropriately positioned soot blowers.

A. Chambers, Alberta Research Council, Canada. With the projected large increase in coal-fired power generation in China, are emissions regulations being imposed to offset the environmental impact?

Author's Reply. Comprehensive environmental laws have been passed by the People's Congress and regulations concerning emissions by power plants and other industries have been set up. Agencies have been established to enforce those laws and regulations and municipalities are trying to solve some pollution problems by supplying centralized heating and cleaner fuel (gas). However, due to the immensity of the problems and meagerness of the available means of enforcement and correction, serious situations already exist and will get worse in the future if greatly increased efforts are not made. Examples of the problems are the acid rain in the southwest from power plants and the pollution in northern cities from the large number of coal-burning stoves from families. Much remains to be done in this very important area. 